\title{
PENGARUH FAKTOR SOSIAL, PRIBADI, DAN PSIKOLOGIS TERHADAP KEPUTUSAN PEMBELIAN SEPEDA MOTOR YAMAHA PADA CV. SUN BERLIAN MOTOR AEK NABARA
}

\author{
Fery Arvandi ${ }^{1}$, Ade Parlaungan Nasution ${ }^{2}$ \\ ${ }^{1}$ Alumni Sarjana Ekonomi STIE Labuhanbatu ${ }^{2}$ Dosen STIE Labuhanbatu
}

\begin{abstract}
ABSTRAK
Perkembangan industri otomotif dewasa ini begitu cepat seiring dengan kemajuan tehnologi dan tingginya tingkat persaingan diantara perusahaan-perusahaan otomotif dalam menciptakan produk yang dapat mempengaruhi keputusan pembelian konsumen. Perilaku masyarakat yang membutuhkan dan menginginkan sepeda motor dengan merek, kualitas, harga serta dengan desain baru yang ditawarkan pada tingkat harga yang kompetitif merupakan potensi yang harus diperhatikan produsen untuk mempengaruhi keputusan pembelian konsumen. Untuk maju dan berkembang dalam konsep pemasaran perusahaan harus mampu memahami kebutuhan dan keinginan konsumen, dimana kepada merekalah nantinya produk tersebut akan dipasarkan. Tujuan dari penelitian ini adalah untuk mengetahui pengaruh faktor sosial, pribadi, dan psikologis terhadap keputusan pembelian sepeda motor Yamaha pada CV. Sun Berlian Motor Aek Nabara. Metode analisis data yang digunakan adalah Uji Realibilitas, Uji Validitas, Analisis Regresi Linear Berganda, Koefisien Determinasi $\left(R^{2}\right)$, uji F dan uji t. Dari hasil analisis diperoleh persamaan regresi bahwa : $\mathrm{Y}=2,414+0,660 \mathrm{X}_{1}+0,340 \mathrm{X}_{2}+0,166 \mathrm{X}_{3}+e$ Semua variabel faktor sosial, pribadi, dan psikologis berpengaruh terhadap keputusan pembelian sepeda motor Yamaha dan nilainya positif. Variabel yang lebih dominan berpengaruh terhadap keputusan pembelian sepeda motor Yamaha adalah variabel faktor sosial, hal ini ditunjukkan oleh koefisien regresi yang lebih besar dibandingkan dengan koefisien, pribadi, dan psikologis. Koefisien determinasi $\left(R^{2}\right)=0,597$. Hal ini menunjukkan bahwa sebesar 57,3\% keputusan pembelian konsumen dapat dijelaskan oleh variabel faktor sosial, pribadi, dan psikologis, sedangkan sisanya $(100 \%-57,3 \%=$ $42,7 \%$ ) dijelaskan faktor-faktor lain yang tidak diteliti. Uji F diperoleh bahwa sosial, pribadi, dan psikologis secara simultan berpengaruh terhadap keputusan pembelian sepeda motor Yamaha. Hail Uji t dari tiap variabel diperoleh bahwa sosial, pribadi, dan psikologis secara parsial masing-masing berpengaruh terhadap variabel keputusan pembelian sepeda motor Yamaha.
\end{abstract}

\section{Kata kunci : Faktor sosial, Pribadi, Psikologis, Keputusan pembelian}

\section{Pendahuluan}

Seiring dengan pertumbuhan ekonomi dan kemajuan teknologi, dunia usahapun mengalami pertumbuhan yang pesat dengan munculnya berbagai perusahaan yang berusaha menciptakan produk dan jasa guna memenuhi kebutuhan konsumen. Dengan demikian persaingan yang ketat akan mendominasi dunia usaha dewasa ini, dimana perusahaan saling berlomba untuk menguasai pangsa pasar. Di lihat dari kenyataan ini maka perusahaan dituntut untuk lebih mengadaptasikan diri dengan bekerja lebihefisien dan efektif, mempunyai kemampuan mengkombinasikan fungsi-fungsi organisasi lainnya agar perusahaan dapat berjalan dengan lancar. 
Tekanan-tekanan dari faktor-faktor internal dapat saja berupa sikap, inovasi-inovasi dan keunggulan dalam bersaing melalui perbaikan produk dan perbaikan sumber daya manusia sedangkan faktor eksternal yaitu sosial, pribadi, dan psikologis. Faktor internal dan eksternal merupakan pendorong yang mengharuskan setiap perusahaan untuk bisa

mengadaptasi dan beradaptasi terhadap setiap perubahan agar dapat tetap eksis, sehingga perubahan yang terjadi tidak merupakan rintangan atau ancaman, tetapi dapat menjadi peluang untuk mengembangkan usaha dan memperoleh keuntungan yang besar.

Pemahaman akan perilaku konsumen mutlak diperlukan apalagi pada saat sekarang ini perkembangan dari dunia otomotif yang begitu pesat dan cepat membuat intensitas persaingan yang semakin tinggi, dan ini menjadi hal penting bagi para pemasar apabila ingin tetap diterima oleh konsumennya. Demikian halnya pada CV. Sun Berlian Motor sebagai salah satu perusahaan yang bergerak dibidang bisnis otomotif yang

dalam melaksanakan kegiatannya dihadapkan pada persaingan dengan perusahaanperusahaan bisnis otomotif lainnya. Dalam upaya mengadaptasi perubahan yang terjadi baik internal maupun eksternal, CV. Sun Berlian Motor senantiasa melakukan berbagai langkah yang tepat dalam menjalankan operasinya agar senantiasa dapat terjadi peningkatan jumlah penjualan.

\section{Tinjauan Pustaka}

Menurut Kristianto (2011:46) menyebutkan bahwa faktor-faktor yang mempengaruhi perilaku konsumen, terdiri dari :

1) Kebudayaan, dengan sub variabel : budaya, sub budaya dan kelas sosial

2) Sosial, dengan sub variabel :

kelompok-kelompok referensi, keluarga, peranan, dan status

3) Pribadi, dengan sub variabel : usia dan tahap daur hidup, pekerjaan, gaya hidup, kepribadiaan dan konsep diri

4) Psikologis dengan sub variabel : motivasi, persepsi, belajar, kepercayaan, dan sikap.

Variabel (1) dan (2) merupakan variabel eksternal sedangkan variabel (3) dan (4) merupakan variabel internal.

Menurut Purimahua (2006 : 546) faktor sosial adalah sekelompok orang yang mampu mempengaruhi perilaku individu dalam melakukan suatu tindakan berdasarkan kebiasaaan.

Menurut Kristianto (2011:50) Faktor pribadi adalah faktor yang dipengaruhi oleh karakteristik pribadi dari eorang konsumen.

Menurut Kristianto (2011:46) Faktor psikologis merupakan cara yang digunakan untuk mengenali perasaan mereka, mengumpulkan dan menganalisis informasi, merumuskan pikiran dan pendapat dalam mengambil tindakan.

Berdasarkan penjelasan di atas, maka kerangka konseptual dalam penelitian ini dapat digambarkan sebagai berikut :

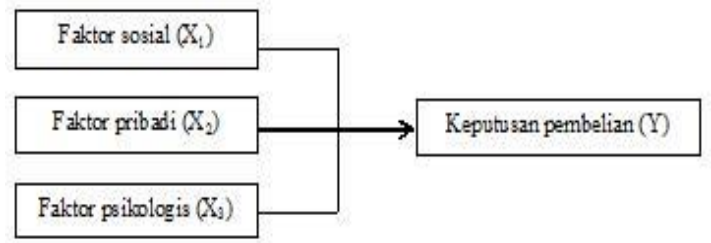

\section{Gambar 1 Kerangka Konseptual}

Berdasarkan latar belakang, landasan teori, dan perumusan masalah, maka peneliti merumuskan hipotesis yang merupakan kesimpulan sementara bagaimana pengaruh tiga variabel bebas terhadap satu variabel terikat. adapaun hipotesis penelitian ini sebagai berikut : 
1. Faktor sosial berpengaruh positif dan signifikan terhadap keputusan pembelian sepeda motor Yamaha pada CV. Sun Berlian Motor Aek Nabara.

2. Faktor pribadi berpengaruh positif dan

signifikan terhadap keputusan pembelian sepeda motor Yamaha pada CV. Sun Berlian Motor Aek Nabara.

3. Faktor psikologis berpengaruh positif dan signifikan terhadap keputusan pembelian sepeda motor Yamaha pada CV. Sun Berlian Motor Aek Nabara.

4. Faktor sosial, pribadi, dan psikologis berpengaruh positif dan signifikan terhadap keputusan pembelian sepeda motor Yamaha pada CV. Sun Berlian Motor Aek Nabara.

\section{Metode Penelitian}

Populasi dan Sampel

Populasi yang dimaksud disini adalah konsumen yang membeli sepeda motor Yamaha tahun 2015 di CV. Sun Berlian Motor Aek Nabara sebanyak 1238 orang.

Dengan menggunakan rumus Slovin diatas, maka jumlah sampel dalam penelitian ini dihitung<smiles></smiles>

Dengan demikian jumlah sampel dibulatkan menjadi 93 responden.

\section{Metode Analisis Data Metode Analisis Deskriptif}

Analisis deskriptif adalah kegiatan

mengelompokkan, memisahkan, mengatur, mengurutkan, menganalisis serta menyimpulkan data sehingga

hasilnya dapat ditafsirkan dan memberikan informasi deskriptif untuk menjawab pertanyaan dari defenisi masalah.

\section{Metode Analisis Statistik Analisis Regresi Linear Berganda}

Analisis regresi linear berganda digunakan untuk melihat pengaruh faktor sosial $\left(\mathrm{X}_{1}\right)$, faktor pribadi $\left(\mathrm{X}_{2}\right)$, dan fakor psikologis $\left(\mathrm{X}_{3}\right)$ terhadap keputusan pembelian $(\mathrm{Y})$. Persamaan matematis analisis regresi linier berganda dituliskan sebagai berikut :

$$
\begin{array}{ll}
\mathbf{Y}=\mathbf{a}+\mathbf{b}_{1} \mathbf{X}_{1}+\mathbf{b}_{2} \mathbf{X}_{2}+\mathbf{b}_{3} \mathbf{X}_{3}+\boldsymbol{e} \text { Dimana : } \\
\mathrm{Y} & =\text { Kinerja karyawan } \\
\mathrm{a} & =\text { Konstanta } \\
\mathrm{b}_{1}, \mathrm{~b}_{2}, \mathrm{~b}_{3} & =\text { Koefisien regresi } \\
\mathrm{X}_{1} & =\text { Faktor sosial } \\
\mathrm{X}_{2} & =\text { Faktor pribadi } \\
\mathrm{X}_{3} & =\text { Faktor psikologis } \\
e & =\text { Standar error }
\end{array}
$$

\section{Uji Hipotesis}

\section{Uji Signifikansi Parsial (Uji t)}

Uji t dilakukan untuk mengetahui

pengaruh masing-masing variabel independen $(X)$ secara parsial terhadap variabel dependen (Y). Uji t dilakukan dengan membandingkan thitung terhadap ttabel dengan ketentuan sebagai berikut :

$\mathrm{H} 0: \beta=0$, berarti tidak ada pengaruh signifikan dari masing-masing variabel independen $(\mathrm{X})$ terhadap variabel dependen $(\mathrm{Y})$ secara parsial.

Ha : $\beta>0$, berarti ada pengaruh yang signifikan dari masing-masing variabel independen $(\mathrm{X})$ terhadap variabel dependen $(\mathrm{Y})$ secara parsial. 
Tingkat kepercayaan yang digunakan adalah $95 \%$ atau taraf signifikan $5 \%(\alpha=0,05)$ dengan kriteria sebagai berikut :

a) Jika thitung $>$ ttabel dan probabilitas (nilai signifikan) < tingkat signifikansi 5\%

$(\alpha=0,05)$, maka Ha diterima dan $\mathrm{H}_{0}$ ditolak berarti ada pengaruh yang signifikan dari masing-masing variabel independen $(\mathrm{X})$ terhadap variabel dependen $(\mathrm{Y})$.

b) Jika thitung $<$ tabel dan probabilitas (nilai signifikansi) $>$ tingkat signifikansi $5 \%$

$(\alpha=0,05)$ maka $\mathrm{H}_{0}$ diterima dan $\mathrm{H}$ a ditolak berarti tidak ada pengaruh yang signifikan dari masing-masing variabel independen $(\mathrm{X})$ terhadap variabel dependen $(\mathrm{Y})$.

Nilai tabel ditentukan dengan mencari derajat bebasnya yaitu $\mathrm{df}=\mathrm{N}-\mathrm{k}$. Dalam melakukan uji parsial (uji t), peneliti menggunakan alat bantu aplikasi SPSS 20.0 for Windows.

\section{Uji Signifikansi Simultan (Uji F)}

Pengujian ini dilakukan untuk

mengetahui apakah semua variabel

independen secara bersama-sama (simultan) dapat berpengaruh terhadap variabel dependen.

Cara yang digunakan adalah dengan membandingkan nilai

Fhitung dengan $\mathrm{F}_{\text {tabel }}$ dengan ketentuan sebagai berikut:

$\mathrm{H}_{0}: \beta=0$, berarti tidak ada pengaruh signifikan dari variabel independen $(\mathrm{X})$ terhadap variabel dependen $(\mathrm{Y})$ secara simultan.

Ha : $\beta>0$, berarti ada pengaruh yang signifikan dari variabel independen

(X) terhadap variabel dependen (Y) secara simultan.

Tingkat kepercayaan yang digunakan adalah $95 \%$ atau taraf signifikan $5 \%(\alpha=0,05)$ dengan kriteria sebagai berikut :

a) Jika $F_{\text {hitung }}>F_{\text {tabel }}$ dan probabilitas (nilai signifikan) $<$ tingkat signifikansi $5 \%(\alpha=0,05)$ maka Ha diterima dan

$\mathrm{H}_{0}$ ditolak berarti ada variabel independen (X) secara bersama-sama mempunyai pengaruh yang signifikan terhadap variabel dependen $(\mathrm{Y})$.

b) Jika Fhitung $<$ Ftabel dan probabilitas

(nilai signifikansi) $>$ tingkat signifikansi 5\% $(\alpha=0,05)$ maka H0 diterima dan Ha ditolak berarti ada variabel independen $(\mathrm{X})$ secara

bersama-sama tidak mempunyai pengaruh yang signifikan terhadap variabel dependen (Y).

Nilai $\mathrm{F}$ tabel ditentukan dengan mencari derajat bebasnya yaitu df $1=\mathrm{k}-1$ dan df $2=\mathrm{N}-\mathrm{k}$, dimana $\mathrm{N}=$ jumlah sampel dan $\mathrm{k}=$ jumlah variabel. Dalam melakukan uji simultan (uji F), peneliti menggunakan alat bantu aplikasi SPSS 20.0 for Windows.

\section{Koefisien Determinasi $\left(\boldsymbol{R}^{2}\right)$}

Koefisien determinasi $\left(R^{2}\right)$ pada intinya mengukur seberapa jauh kemampuan

variabel independen yaitu faktor sosial $\left(\mathrm{X}_{1}\right)$, faktor pribadi $\left(\mathrm{X}_{2}\right)$, dan faktor psikologis $\left(\mathrm{X}_{3}\right)$ dalam menerangkan variabel dependen $(\mathrm{Y})$ yaitu keputusan pembelian. Nilai koefisien determinasi adalah antara nol (0) dan satu

(1). Nilai $R^{2}$ yang kecil berarti kemampuan variabel-variabel independen dalam menjelaskan variasi variabel dependen amat terbatas. Secara umum koefisien determinasi untuk data silang (crosssection) relatif rendah karenaadanya variasi yang besar antara masing-masing pengamatan, sedangkan untuk data runtun waktu (time series) biasanya mempunyai nilai koefisien determinasi yang tinggi. Untuk variabel bebas lebih dari dua menggunakan Adjusted $R^{2}$. 


\section{Hasil Dan Pembahasan \\ Hasil Penelitian}

Hasil Analisis Regresi Linear Berganda Dalam melakukan analisis regresi linear berganda digunakan bantuan aplikasi SPSS versi 20. Hasil pengolahan data ditampilkan seperti pada Tabel berikut :

\section{Tabel 1}

\begin{tabular}{|c|c|c|c|c|c|c|}
\hline \multirow{2}{*}{\multicolumn{2}{|c|}{ Model }} & \multicolumn{2}{|c|}{$\begin{array}{l}\text { Unstandardized } \\
\text { Coefficients }\end{array}$} & \multirow{2}{*}{$\begin{array}{c}\begin{array}{c}\text { Standardized } \\
\text { Coefficients }\end{array} \\
\text { Beta }\end{array}$} & \multirow[t]{2}{*}{$\mathrm{t}$} & \multirow[t]{2}{*}{ Sig. } \\
\hline & & B & $\begin{array}{l}\text { Std. } \\
\text { Error }\end{array}$ & & & \\
\hline \multirow{4}{*}{1} & (Constant) & 2,414 & 1,682 & & 1,435 & , 155 \\
\hline & Faktor sosial &, 660 & ,112 & 440 & 5,919 & ,000 \\
\hline & Faktor pribadi & ,340 & ,061 & ,420 & 5,562 & , 000 \\
\hline & $\begin{array}{l}\text { Faktor } \\
\text { psikologis }\end{array}$ & ,166 & ,072 & 162 & 2,324 & ,022 \\
\hline
\end{tabular}

Sumber : Hasil Penelitian (Diolah SPSS), 2016

Berdasarkan Tabel 4.8 pada

kolom Unstandardized Coefficients diperoleh nilai konstansta dan koefisien regresi, sehingga terbentuk persamaan sebagai berikut :

$\mathrm{Y}=\mathbf{2 , 4 1 4}+\mathbf{0 , 6 6 0 \times 1}+\mathbf{0 , 3 4 0 \times 2}+0,166 \times 3+e$

Interpretasi persamaan tersebut adalah sebagai berikut :

1) Konstanta (a) $=2,414$. menunjukkan bahwa jika $X$ (faktor sosial, pribadi, dan psikologis) konstan atau $X=0$, maka keputusan pembelian sebesar 2,414.

2) Koefisien ( $\left.b_{1}\right)=0,660$. Ini menunjukkan bahwa setiap perubahan satu variabel faktor sosial $\left(\mathrm{X}_{1}\right)$, akan menambah keputusan pembelian sebesar 0,660 .

3) Koefisien $\left(b_{2}\right)=0,340$. Ini

menunjukkan bahwa setiap perubahan satu variabel faktor pribadi $\left(\mathrm{X}_{2}\right)$, akan menambah keputusan pembelian sebesar 0,340.

4. Koefisien $\left(b_{3}\right)=0,166$. Ini menunjukkan bahwa setiap perubahan

satu variabel faktor psikologis $\left(\mathrm{X}_{3}\right)$, akan menambah keputusan pembelian sebesar 0,166 .

\section{Pengujian Hipotesis}

Uji Hipotesis yang digunakan adalah uji signifikansi parsial (uji t), uji signifikansi simultan (uji F), dan koefisien determinasi $\left(R^{2}\right)$.

\section{Uji Signifikansi Parsial (Uji t)}

Uji parsial (Uji t) digunakan untuk menguji tingkat signifikasi variabel X (lokasi, harga dan fasilitas) terhadap Y (loyalitas konsumen) secara parsial.

Pengujian dilakuakn dengan mebandingkan nilai thitung dengan tabel. Nilai thitung diperoleh dari pengolahan SPSS, sedangkan nilai t tabel menggunakan nilai distribusi t dengan taraf signifikansi

0,05 pada derajat kebebasan $(\mathrm{df}=\mathrm{n}-\mathrm{k}=$ $93-4=89)$, maka nilai tabel $(5 \%: 89)$ sebesar $1,66216=1,662$. 
Tabel 2

Hasil Uji Parsial (Uji t)

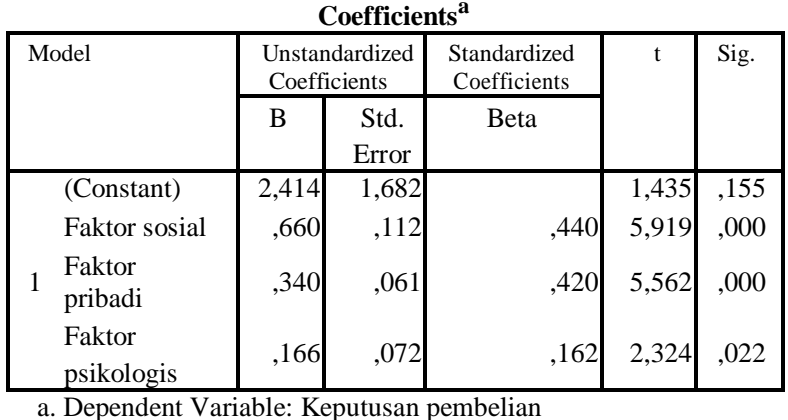

Sumber : Hasil Penelitian (Diolah SPSS), 2016

Berdasarkan hasil output SPSS

pada Tabel diatas, maka nilai thitung dari tiap variabel independen (faktor sosial, pribadi, dan psikologis) dibandingkan dengan nilai ttabel sebagai berikut :

1) Variabel faktor sosial $\left(X_{1}\right)$ diperoleh hasil nilai thitung $(5,919)>$ tabel $(1,662)$ dengan taraf signifikan $0,000<0,05$, dapat disimpulkan bahwa variabel faktor sosial berpengaruh secara positif dan signifikan terhadap keputusan pembelian sepeda motor Yamaha pada CV. Sun Berlian Motor Aek Nabara.

2) Variabel faktor pribadi $\left(X_{2}\right)$ diperoleh hasil nilai thitung $(5,562)>t$ tabel $(1,662)$ dengan taraf signifikan $0,000<0,05$ dapat disimpulkan bahwa variabel faktor pribadi berpengaruh secara positif dan signifikan terhadap keputusan pembelian sepeda motor Yamaha pada CV. Sun Berlian Motor Aek Nabara.

3) Variabel psikologis $\left(X_{3}\right)$ diperoleh hasil nilai thitung $(2,324)>$ tabel $(1,662)$ dengan taraf signifikan $0,022<0,05$ dapat disimpulkan bahwa variabel faktor psikologis berpengaruh secara positif dan signifikan terhadap keputusan pembelian sepeda motor Yamaha pada CV. Sun Berlian Motor Aek Nabara.

\section{Uji Signifikansi Simultan (Uji F)}

Uji simultan (Uji F) digunakan untuk menguji pengaruh faktor sosial $\left(\mathrm{X}_{1}\right)$, faktor pribadi $\left(\mathrm{X}_{2}\right)$ dan faktor psikologis $\left(\mathrm{X}_{3}\right)$ secara bersama-sama terhadap keputusan pembelian sepeda motor Yamaha pada CV. Sun Berlian Motor Aek Nabara (Y). Uji F dilakukan

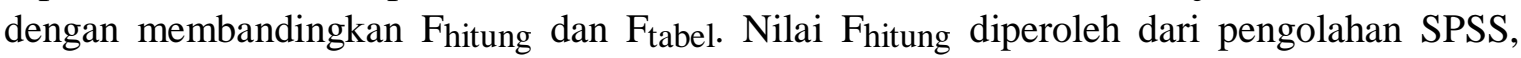
sedangkan $\mathrm{F}_{\text {tabel }}$ diperoleh dari nilai distribusi $\mathrm{F}$ pada derajat kebebasan $\mathrm{df}_{1}$ (4$1=3)$ dan df $2(93-4=89)$. Maka $F_{\text {tabel }}$ yang digunakan adalah nilai $F(3: 89)=$ 2,71 .

Tabel 3

Hasil Uji Simultan (Uji F)

\begin{tabular}{|l|r|r|r|c|c|}
\hline Model & $\begin{array}{r}\text { Sum of } \\
\text { Squares }\end{array}$ & Df & $\begin{array}{r}\text { Mean } \\
\text { Square }\end{array}$ & F & Sig. \\
\hline Regression & 126,371 & 3 & 42,124 & 42,213 &, $000^{\mathrm{b}}$ \\
1 Residual & 88,812 & 89 &, 998 & & \\
\hline
\end{tabular}




\section{Berdasarkan Tabel di atas}

diketahui bahwa Fhitung $(42,213)>\mathrm{F}_{\text {tabel }}(2,71)$ dengan taraf signifikan $0,000<$ 0,05 . Hal ini menunjukkan bahwa variabel independen yang terdiri dari faktor sosial $\left(\mathrm{X}_{1}\right)$, faktor pribadi $\left(\mathrm{X}_{2}\right)$ dan faktor psikologis $\left(\mathrm{X}_{3}\right)$ secara simultan atau bersama-sama berpengaruh positif dan signifikan terhadap keputusan pembelian sepeda motor Yamaha pada CV. Sun Berlian Motor Aek Nabara.

\section{Koefisien Determinasi $\left(R^{2}\right)$}

Koefisien determinasi digunakan

untuk mengetahui sejauhmana kemampuan variabel bebas $(X)$ dalam menjelaskan variabel terikat $(\mathrm{Y})$. Besarnya Koefisien determinasi dapat dilihat pada Tabel berikut ini :

\section{Tabel 4}

\section{Koefisien Determinasi}

\begin{tabular}{|l|c|r|r|r|}
\hline Model & $\mathrm{R}$ & $\begin{array}{c}\mathrm{R} \\
\text { Square }\end{array}$ & $\begin{array}{c}\text { Adjusted } \\
\mathrm{R} \text { Square }\end{array}$ & $\begin{array}{c}\text { Std. Error of the } \\
\text { Estimate }\end{array}$ \\
\hline 1 &, $766^{\mathrm{a}}$ &, 587 &, 573 &, 999 \\
\hline
\end{tabular}
a. Predictors: (Constant), Faktor psikologis, Faktor sosial, Faktor pribadi
Sumber : Hasil Penelitian (Diolah SPSS), 2016

Pada Tabel di atas dapat disimpulkan sebagai berikut:

1) Nilai $R$ sebesar 0,766 berarti hubungan antara faktor sosial $\left(\mathrm{X}_{1}\right)$, faktor pribadi $\left(\mathrm{X}_{2}\right)$ dan faktor psikologis $\left(\mathrm{X}_{3}\right)$ keputusan pembelian sepeda motor Yamaha pada CV. Sun Berlian Motor Aek Nabara sebesar 76,6\%. Hal ini berarti hubungannya erat.

2) Adjusted $R^{2}$ sebesar 0,573 berarti57,3\% keputusan pembelian sepeda motor Yamaha pada CV. Sun Berlian Motor Aek Nabara Motor dapat dijelaskan oleh faktor sosial $\left(\mathrm{X}_{1}\right)$, faktor pribadi $\left(\mathrm{X}_{2}\right)$ dan faktor psikologis $\left(\mathrm{X}_{3}\right)$, sedangkan sisanya sebesar $42,7 \%$ dapat dijelaskan faktor-faktor yang tidak dibahas oleh penelitian ini.

\section{B. Pembahasan}

Melihat kenyataan dunia bisnis yang terus berkembang, maka tuntutan akan faktorfaktor yang mempengaruhi konsumen dalam membeli semakin beragam dan terus-menerus berkembang sesuai dengan perubahan zaman. Di dalam hidupnya manusia tidak lepas dari berbagai macam kebutuhan, mulai dari kebutuhan dasar sampai pada tingkat kebutuhan yang lebih tinggi. Salah satu kebutuhan manusia adalah tampil menarik, percaya diri dan nyaman. Kebutuhan itu dapat terpenuhi dengan menggunakan kendaraan roda dua yaitu sepeda motor.

Semakin ketatnya persaingan diantara perusahaan industri otomotif, membuat pelaku industri otomotif harus lebih cermat lagi dalam mengamati perkembangan pasar dan menerapkan strategi-strategi pemasaran yang jitu agar market share yang telah diraih tidakdirebut oleh pesaing-pesaing lama ataupun pesaing yang baru. Tidak terkecuali Yamaha yang merupakan salah satu perusahaan industri otomotif yang terkemuka, dapat membentuk komponen keunggulan bersaing yang kuat agar dapat membedakannya dari pesaing. Salah satu komponen keunggulan bersaing tersebut dapat dibentuk dengan melihat faktor-faktor yang mempengaruhi konsumen dalam membeli.

Semakin dikenalnya produk sebagai akibat dari persepsi dan keyakinan atas produk tertentu, akan menimbulkanimage terhadap pemakainya. Faktor-faktor menjadi sangat penting diperhatikan perusahaan, karena dengan mengetahui faktor-faktor, maka dapat 
menimbulkan nilai emosional pada diri konsumen, dimana akan timbul perasaan positif pada saat membeli atau menggunakan produk tertentu.

Dalam penelitian ini dibahas mengenai pengaruh faktor sosial, pribadi, dan psikologis terhadap keputusan pembelian sepeda motor Yamaha, senagai berikut :

\section{Pengaruh Faktor Sosial Terhadap Keputusan Pembelian Sepeda Motor Yamaha}

Berdasarkan hasil uji hipotesis, diketahuin bahwa faktor sosial berpengaruh positif dan signifikan terhadap keputusan pembelian sepeda motor Yamaha pada CV. Sun Berlian Motor Aek Nabara. Hal ini dibuktikan

dari nilai thitung $(5,919)>t$ tabel $(1,662)$ dengan taraf signifikan $0,000<0,05$.

Variabel faktor sosial merupakan variabel yang lebih dominan berpengaruh dan menjadi pertimbangan konsumen dalam memilih sepeda motor Yamaha. Variabel faktor sosial memiliki pengaruh terhadap keputusan pembelian sepeda motor Yamaha, dimana faktor ini meliputi pengaruh dari lingkungan pergaulan, keluarga, serta peran dan status dalam masyarakat. Pengaruh dari lingkungan masyarakat terhadap scutermatic Yamaha biasa muncul ketikalingkungan tempat tinggal memiliki kepercayaan terhadap satu merek yang populer saat ini, selain itu keluarga menjadi pengaruh yang sangat besar dalam keputusan pembelian suatu produk, serta peran dan statusnya dalam masyarakat yang ingin dihargai, sehingga memilih jenis produk sepeda motor Yamaha yang terbaik.

\section{Pengaruh Faktor Pribadi Terhadap Keputusan Pembelian Sepeda Motor Yamaha}

Berdasarkan hasil uji hipotesis, diketahuin bahwa faktor pribadi berpengaruh positif dan signifikan terhadap keputusan pembelian sepeda motor Yamaha pada CV. Sun Berlian

Motor Aek Nabara. Hal ini dibuktikan dari nilai thitung $(5,562)>\operatorname{tabel}(1,662)$ dengan taraf signifikan $0,000<0,05$. Keputusan dalam membeli sepeda motor Yamaha menjadi pertimbangan sendiri yang melihat dari usia kebutuhan, pekerjaan, keadaan ekonomi, gaya hidup, serta rasa percaya diri ketika menggunakan produk tersebut. Sepeda Motor Yamaha mempunyai fitur/gaya yang sesuai dengan kebutuhan konsumen seperti bentuk dan striping yang bagus serta mempunyai desain yang unik dengan berbagai pilihan warna. Oleh sebab itu faktor pribadi harus sangat diperhatikan oleh perusahaan, yaitu dengan melakukan riset terusmenerus untuk mengetahui perkembangan dan keinginan konsumen terhadap produk sepeda motor Yamaha.

\section{Pengaruh Faktor Psikologis Terhadap Keputusan Pembelian Sepeda Motor Yamaha}

Berdasarkan hasil uji hipotesis, diketahuin bahwa faktor psikologis berpengaruh positif dan signifikan terhadap keputusan pembelian sepeda motor Yamaha pada CV. Sun Berlian Motor Aek Nabara. Hal ini dibuktikan dari nilai thitung $(2,324)>t$ tabel $(1,662)$ dengan taraf signifikan $0,022<0,05$.

Variabel psikologis menjadi faktor yang perlu diperhatikan oleh perusahaan terutama perusaahaan otomotif, karena faktor tersebut dipengaruhi oleh motivasi dalam membeli, persepsi terhadap iklan, pengetahuan suatu produk, keyakinan dan sikap dalam keputusan pembelian motor scuter matic. Untuk itu CV. Sun Berlian Motor mengeluarkan produk produk terbaru seperti : Xeon dan Mio.Nama seperti Mio standar, Mio Soul, Mio Sporty CW, Mio CW SE3, Mio Vino, dan Mio J adalah bagian dari tipe merek Mio, Vixion, Zupiter MX Keempat faktor di atas menjadi pertimbangan konsumen dalam memilih dan membeli sepeda motor Yamaha, Konsumen mempunyai perilaku yang setiap saat dapat berubah.

Perubahan tersebut bisa terjadi dikarenakan faktor budaya, sosial, pribadi dan psikologi. Pemahaman atas perilaku konsumen menjadi sangat penting bagi keberhasilan strategi 
pemasaran suatu perusahaan. Oleh karena itu, perusahaan tidak hanya harus dapat memenuhi dan memuaskan keinginan ekonomi saja, melainkan juga kebutuhan sosial dan motivasi lain yang diharapkan konsumen.

\section{Kesimpulan Dan Saran \\ Kesimpulan}

Berdasarkan hasil penelitian, maka dapat diambil kesimpulan sebagai berikut :

1. Faktor sosial berpengaruh positif dan signifikan secara parsial terhadap keputusan pembelian sepeda motor Yamaha pada CV. Sun Berlian Motor Aek Nabara.

2. Faktor pribadi berpengaruh positif dan signifikan secara parsial terhadap keputusan pembelian sepeda motor Yamaha pada CV. Sun Berlian Motor Aek Nabara.

3. Faktor psikologis berpengaruh positif dan signifikan secara parsial terhadap keputusan pembelian sepeda motor Yamaha pada CV. Sun Berlian Motor Aek Nabara.

4. Faktor sosial, pribadi, dan psikologis secara bersama-sama berpengaruh positif dan signifikan terhadap keputusan pembelian sepeda motor Yamaha pada CV. Sun Berlian Motor Aek Nabara.

5. Keputusan pembelian sepeda motor Yamaha dapat dijelaskan oleh faktor sosial, pribadi, dan psikologis sebesar 57,3\%, sedangkan sisanya sebesar $42,7 \%$ dapat dijelaskan faktorfaktor yang tidak diteliti oleh penelitian ini.

\section{Saran}

Berdasarkan kesimpulan diatas, maka peneliti memberikan saran sebagai berikut :

1. Disarankan kepada perusahaan dalam hal ini produsen Yamaha yang diwakili oleh dealer-dealer resminya harus selalu melakukan riset terus-

menerusuntukmengetahui

perkembangan dan keinginan konsumen terhadap produk sepeda motor Yamaha.

2. Disarankan kepada perusahaan untuk mengamati kecenderungan dalam pendapatan masyarakat. Bila indikator ekonomi menunjukkan resesi, pemasar dapat mengambil langkah-langkah

untuk merancang ulang, dan mengubah harga sesuai dengan situasi ekonomi target pasar yang telah ditentukan, agar konsumen memilih

produk yang ditawarkan oleh perusahaan.

3. Perusahaan harus memperhatikan trend atau gaya hidup. Hal ini sangat pentingdiperhatikanterutama

dikalangan remaja dengan menciptakan desain yang beda dari produk scuter matic lain. Hal ini menjadi pertimbangan bagi konsumen untuk memilih motor yang dianggap memliki desain yang unik dan lebih baik. Untuk itu ketiga hal tersebut perlu diperhatikan oleh perusahaan agar dapat diterima oleh konsumen dengan baik.

4. Untuk penelitian selanjutnya, disarankan memasukkan faktor-faktor lain yang mempengaruhi konsumen dalam keputusan pembelian agar hasilnya lebih maksimal. 


\section{Daftar Pustaka}

Arikunto,Suharsimi. 2006. ProsedurPenelitian. Jakarta : Rineka Cipta.

Boyd, et.al. 2006. Manajemen Pemasaran; Suatu Pendekatan

Strategis Dengan Orientasi Global. Jakarta : Erlangga.

Damanik, Berdian. 2008. "Analisis Faktor Pribadi dan Faktor Psikologis Terhadap Proses Keputusan Konsumen Pada Gamestation J1. DjaminGinting Padang Bulan Medan". Jurnal FEUSU. Medan.

Ghozali, Imam. 2007. Aplikasi Analisis Multivariate denganProgram SPSS. Semarang : Badan PenerbitUniversitas Diponegoro.

Hurriyati Ratih. 2010. Bauran Pemasaran dan Loyalitas Konsumen.Bandung : Alfabeta.

Kotler, Philip. 2007. Manajemen Pemasaran, Analisis, Perencanaan, Pengendalian.Jakarta : Salemba Empat.

Kotler,Philips dan Gery Armstrong. 2008. Prinsip-prinsip Pemasaran. Edisi kedelapan. Jakarta : Erlangga.

Krtistianto. 2011. Psikologi Pemasaran.

Yogyakarta : PT. Buku Seru.

Kuncoro, Mudrajad. 2009. Metode Risetuntuk Bisnis \& Ekonomi (Edisi 3).Jakarta : Erlangga.

Prayoga, Putra Saguh. 2009. "Pengaruh Faktor Budaya, Sosial, Pribadi, dan Psikologis Terhadap Pengambilan Keputusan Pembelian Mie Instan Merek Sedaap (Studi Kasus Mahasiswa Yang Kost Di Lingkungan Kampus USU)”. Jurnal FEBUSU. Medan 